\title{
Aortic cusp extension valvuloplasty with or without tricuspidization in children and adolescents: Long-term results and freedom from aortic valve replacement
}

\author{
Anastasios C. Polimenakos, MD, ${ }^{\mathrm{a}, \mathrm{b}}$, Shyam Sathanandam, MD, ${ }^{\mathrm{a}}$ Chawki ElZein, MD, ${ }^{\mathrm{a}, \mathrm{b}}$ Mary J. Barth, MD, ${ }^{\mathrm{a}}$ \\ Robert S. D. Higgins, MD, ${ }^{c}$ and Michel N. Ilbawi, $\mathrm{MD}^{\mathrm{a}, \mathrm{b}}$
}

Objective: Aortic cusp extension valvuloplasty is increasingly used in the management of children and adolescents with aortic stenosis or regurgitation. The durability of this approach and the freedom from valve replacement are not well defined. A study was undertaken to investigate outcomes.

\begin{abstract}
Methods: From July 1987 to November 2008, 142 patients aged less than 19 years underwent aortic cusp extension valvuloplasty in the form of pericardial cusp extension and tricuspidization (when needed). Three patients with truncus arteriosus and severe truncal valve insufficiency were excluded. From the available follow-up data of 139 patients, 50 had bicuspid aortic valves, 40 had congenital aortic valve stenosis, 41 had combined congenital aortic valve stenosis/insufficiency, and 8 had other diagnoses. Median follow-up was 14.4 years (0.121.4). Long-term mortality and freedom from aortic valve replacement were studied.
\end{abstract}

Results: There were no early, intermediate, or late deaths. Z-values of left ventricular end-diastolic dimension, aortic annulus, aortic sinus diameter, and sinotubular junction diameter before aortic valve replacement were $4.2 \pm 3.11,2.3 \pm 1.25,4.4 \pm 1.23$, and $1.84 \pm 1.28$, respectively. During the follow-up period, 64 patients underwent aortic valve reinterventions. The Ross procedure was performed in 32 of 139 patients $(23 \%)$ undergoing aortic cusp extension valvuloplasty. Other aortic valve replacements were undertaken after 16 aortic cusp extension valvuloplasties $(11.5 \%)$. Freedom from a second aortic cusp extension valvuloplasty or aortic valve replacement at 18 years was $82.1 \% \pm 4.2 \%$ and $60.0 \% \pm 7.2 \%$, respectively.

Conclusion: Aortic cusp extension valvuloplasty is a safe and effective surgical option with excellent survival and good long-term outcomes in children and adolescents. The procedure provides acceptable durability and satisfactory freedom from aortic valve replacement. (J Thorac Cardiovasc Surg 2010;139:933-41)

Since the initial report of aortic valve repair, ${ }^{1}$ there have been various techniques described. Available surgical options for the treatment of aortic insufficiency (AI) or aortic stenosis (AS) in young patients include various techniques of aortic valve repair, surgical aortic valvuloplasty, and aortic valve replacement (AVR) with mechanical, bioprosthetic, or autologous pulmonary valves. ${ }^{2-5}$ Results have been improving with better anatomic understanding and operative and postoperative management. Aortic cusp extension valvuloplasty (ACEV) with tricuspidization (when

\footnotetext{
From the Division of Pediatric Cardiovascular Surgery, ${ }^{\text {a }}$ Section of Cardiac Surgery, Department of Surgery, The Heart Institute for Children at Advocate Hope Children's Hospital, Oak Lawn, Ill; Division of Pediatric Cardiovascular Surgery and Thoracic Surgery, ${ }^{\mathrm{b}}$ Center for Congenital and Structural Heart Disease, Rush University Medical Center, Chicago, Ill; and Department of Cardiovascular and Thoracic Surgery, ${ }^{\mathrm{c}}$ Rush University Medical Center, Chicago, Ill.

Disclosures: None.

Received for publication June 28, 2009; revisions received Nov 12, 2009; accepted for publication Dec 13, 2009.

Address for reprints: Anastasios C. Polimenakos, MD, Assistant Professor of Surgery, Rush Center for Congenital and Structural Heart Disease, The Heart Institute for Children, Hope Children's Hospital, Congenital and Pediatric Cardiovascular Surgery, Heart Transplantation, ECMO and Ventricular Assist Devices, Rush University Medical College, 1653 West Congress Parkway, Seven Jones, Chicaco, IL 60612-3244 (E-mail: anastasios_c_polimenakos@rush.edu). $0022-5223 / \$ 36.00$

Copyright (c) 2010 by The American Association for Thoracic Surgery doi:10.1016/j.jtcvs.2009.12.015
}

needed) may have important advantages in children relative to the alternatives, particularly with regard to freedom from reoperation related to a small mechanical prosthesis, avoidance of anticoagulation, and potential mid and late disadvantages of the Ross procedure related to the pulmonary autograft and implanted homograft. Few reports of ACEV in children, most with limited follow-up, have been published. ${ }^{6-12}$ Clinical analysis on patients who underwent ACEV was conducted. Assessment of valvar morphologic characteristics was performed. The impact of ACEV on survival and freedom from reoperation was assessed, and factors associated with improved outcome were explored.

\section{MATERIALS AND METHODS}

The Heart Institute for Children database was analyzed, and all patients undergoing ACEV with or without tricuspidization from July 1987 to November 2008 were included. A retrospective chart review analysis was conducted with regard to preoperative and postoperative data. Current follow-up data were available for all patients.

Preoperative echocardiography was used. AI was graded as (1) none or trace; (2) mild (no left ventricular [LV] dilation, no retrograde flow in the descending aorta, AI vena contracta width $<4 \mathrm{~mm}$ ); (3) moderate (LV end-diastolic volume or LV end-diastolic dimension [LVEDD] z-value $>$ 2 and $<4$, retrograde flow in the descending aorta, vena contracta 4-6 $\mathrm{mm}$ ); or (4) severe (LV end-diastolic volume or LVEDD z-value $>4$, retrograde flow in the descending aorta, vena contracta $>6 \mathrm{~mm}$ ). AS was estimated by Doppler evaluation, and the peak instantaneous gradient (PIG) was recorded. AS was categorized as mild ( $\mathrm{PIG}<40 \mathrm{~mm} \mathrm{Hg}$ ), moderate 


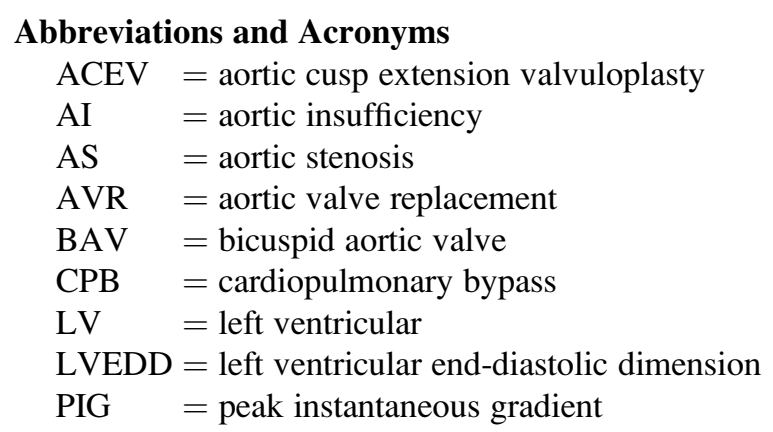

(PIG 41-75 mm Hg), or severe (PIG > $76 \mathrm{~mm} \mathrm{Hg}$ ). Aortic valve annulus and root diameters were measured from parasternal long-axis images, with the root diameter taken as the maximum dimension at the level of the sinuses.

LV dimensions, volumes, and mass were measured and calculated from apical 4-chamber and cross-sectional echocardiographic images. Short-axis LVEDD and LV end-systolic dimension were measured. All data were indexed to body surface area and reported as z-value.

This study was approved by the institutional review board of Advocate Hope Children's Hospital. The institutional review board waived the need for patient consent.

\section{Clinical Management Protocol and Surgical Technique}

Patient Characteristics. From July 1987 to November 2008, 142 patients aged less than 19 years underwent ACEV in the form of pericardial cusp extension and tricuspidization (when needed). Three patients with truncus arteriosus and severe truncal valve insufficiency, who require valvuloplasty, were excluded. Patients with isolated commissuroplasty/ commissurotomy, isolated cusp tear repair, or annular reduction without alteration of the valve leaflets were excluded. Patients with univentricular pathway, morphologically right ventricle functioning as systemic ventricle, and other associated causes of LV volume overload were excluded. During the same period, 29 patients had AVR without prior ACEV. From the available follow-up data of 139 patients, 50 had an initial diagnosis of bicuspid aortic valves (BAVs), 40 had congenital AS, 41 had combined congenital AS and aortic insufficiency (AI), and 8 had other diagnoses (Table 1). AI causes were classified as (1) congenital, (2) BAVs, (3) due to trauma during other cardiac interventions, (4) due to transcatheter or surgical treatment of congenital valvular AS, (5) endocarditis related, (6) rheumatic carditis related, or (7) secondary to an abnormal neoaortic (native pulmonary) valve or root after arterial switch operation. Twenty-six patients $(18.7 \%)$ had associated cardiovascular anomalies, and 1 patient had Turner's syndrome (Table 1). Patients were not initially randomized; rather, each case was managed according to each of 4 surgeons' preference and not on strict anatomic or functional criteria. Later in the series (since 1998), patients selected for ACEV had a normally sized aortic annulus ( $\mathrm{z}$-value $\geq-1.5$ ) without LV hypoplasia or mitral valve hypoplastic annulus (z-value $\leq-2.0$ ). Assessment of severity of valve dysfunction and timing for ACEV involved several echocardiographic/Doppler-derived indices. Indications for ACEV were moderate or severe AI, moderate AS, or a combination of moderate-to-severe AS and moderate AI. Specifically, patients with isolated AS of 40 $\mathrm{mm} \mathrm{Hg}$ or greater with a normally sized valve annulus (as described above) associated with progressive LV hypertrophy were considered for ACEV. In isolated AI, a ratio of regurgitant jet/annulus diameter of $35 \%$ or greater and progressive increase in LVEDD $\mathrm{z}$-value of +2.5 or greater in 2 consecutive measurements constituted objective indications for intervention. The mean
TABLE 1. Demographics and patient characteristics

\begin{tabular}{|c|c|}
\hline Aortic cusp extension valvuloplasty & \\
\hline \multicolumn{2}{|l|}{ Patient characteristics } \\
\hline Age at surgery $(\mathrm{y})$ & $9.3 \pm 2.7$ \\
\hline Age at surgery $(y): 0-2$ & $25(18 \%)$ \\
\hline Age at surgery $(y): 3-6$ & $36(25.9 \%)$ \\
\hline Age at surgery $(\mathrm{y}): 7-11$ & $20(14.4 \%)$ \\
\hline Age at surgery $(y): 12-19$ & $58(41.7 \%)$ \\
\hline Weight at surgery $(\mathrm{kg})$ & $32.71 \pm 9.74$ \\
\hline Gender & 86 male $/ 53$ female \\
\hline Turner's syndrome & 1 \\
\hline \multicolumn{2}{|l|}{ Primary aortic valve diagnosis } \\
\hline BAV & 50 \\
\hline Combined congenital AS/AI & 41 \\
\hline Congenital AS & 40 \\
\hline d-TGA/post-ASO AI & 2 \\
\hline Rheumatic carditis (AI) & 2 \\
\hline Aortic valve endocarditis/aortic root abscess & $3(2 / 1)$ \\
\hline Iatrogenic post-VSD closure AS & 1 \\
\hline \multicolumn{2}{|l|}{ Associated cardiac anomalies } \\
\hline Coarctation of aorta & 10 \\
\hline Ventricular septal defect & 5 \\
\hline Subaortic stenosis & 2 \\
\hline Congenital mitral valve stenosis & 2 \\
\hline Interrupted aortic arch & 1 \\
\hline Coronary fistula & 1 \\
\hline Atrioventricular septal defect & 1 \\
\hline Idiopathic dilated cardiomyopathy & 1 \\
\hline Taussig-Bing anomaly & 1 \\
\hline \multicolumn{2}{|l|}{ Additional surgical procedures } \\
\hline \multicolumn{2}{|l|}{ Before first ACEV } \\
\hline $\begin{array}{l}\text { Initial valvuloplasty-valvotomy } \\
\text { (our facility/outside facility) }\end{array}$ & $67(24 / 43)$ \\
\hline Aortic coarctation repair & 10 \\
\hline ASO & 3 \\
\hline IAA repair with VSD closure & 1 \\
\hline \multicolumn{2}{|l|}{ With the first ACEV } \\
\hline Mitral valvuloplasty for MS or MR & 3 \\
\hline $\begin{array}{l}\text { Ascending aorta reconstruction for } \\
\text { supravalvar AS }\end{array}$ & 2 \\
\hline Subaortic membrane resection & 2 \\
\hline Coronary fistula ligation & 1 \\
\hline
\end{tabular}

$A I$, Aortic insufficiency; $A S$, aortic stenosis; $A C E V$, aortic cusp extension valvuloplasty; $B A V$, bicuspid aortic valve; $d-T G A$, d-transposition of the great arteries; $V S D$, ventricular septal defect; $A S O$, arterial switch operation; $M S$, mitral stenosis; $M R$, mitral regurgitation; $I A A$, interrupted aortic arch.

age at the time of ACEV was $9.3 \pm 2.7$ years. Seventy-five patients were aged less than 10 years. The mean weight of patients undergoing ACEV was $32.71 \pm 9.74 \mathrm{~kg}$. The median follow-up was 14.4 years $(0.1-21.4$ years) (Table 1).

\section{Operative Technique}

Via a median sternotomy, a piece of autologous pericardium is harvested, thoroughly cleaned of all fatty tissue and adhesions, treated with $0.625 \%$ glutaraldehyde solution for 3 minutes, and kept moist with normal saline. 

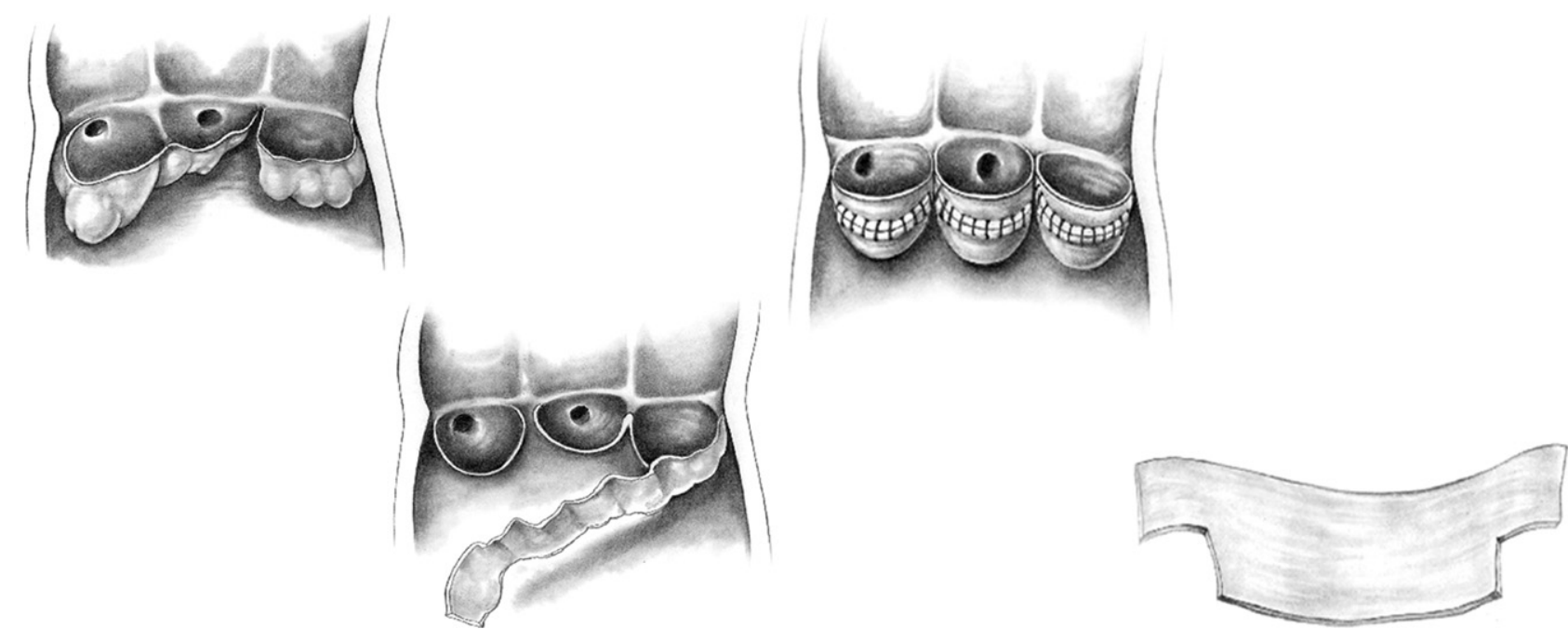

FIGURE 1. ACEV with tricuspidization. Each valve cusp is evaluated as to the extent of tissue deficiency, the shape, and the irregularities of the free edge. The thickened edges of the cusps are thinned out. The valve is tricuspidized by cutting the fused cusp at the raphae all the way to the aortic wall. The fused portion of the cusps at the commissural level is opened to the wall as well. A piece of the treated autologous pericardium is tailored to fit the specific architecture of each cusp, but slightly oversized in depth (10\%-15\%) and length (up to $25 \%$ ).

Aortobicaval cardiopulmonary bypass $(\mathrm{CPB})$ with moderate hypothermia of $32^{\circ} \mathrm{C}$ is used. The aortic cannula is inserted at the distal aspect of the ascending aorta close to the innominate artery. Myocardial preservation is maintained with antegrade and retrograde cold, mostly continuous, blood cardioplegia.

An oblique aortotomy incision is made, and each valve cusp is evaluated as to the extent of tissue deficiency, the shape, and the irregularities of the free edge. The thickened edges of the cusps are thinned out. The valve is tricuspidized by cutting the fused cusp at the raphae all the way to the aortic wall. The fused portion of the cusps at the commissural level is opened to the wall. Any subcommissural fusion or scar tissue is released to provide maximal mobility of the cusps.

The ACEV technique consists of using a piece of the treated autologous pericardium that is then tailored to fit the specific architecture of each cusp (Figure 1), but slightly oversized in depth $(10 \%-15 \%)$ and length (up to $25 \%$ ). In particular, the width should provide enough additional depth to the cusp so that the reconstructed cusp free edge is leveled with the sinotubular bar at the commissures but deeper (more caudad) at the center. It is then sutured to the cusp using continuous 5.0/6.0 polypropylene sutures from its center toward the commissures. The sutures are placed in a radial fashion so the distance between the suture-line on the pericardium is slightly wider than that on the cusp to allow for a generous mural edge.

After completion of the pericardial extension of the 3 cusps, the depth of each sinus is assessed. As a general rule, the center of the free edge of the constructed cusp should reach the level of the sinotubular bar when pulled superiorly. Any excess pericardial tissue is cut at this stage, leaving the commissural ends slightly more superior than the center, thus giving the cusp edge the normal semilunar appearance (Figure 2).

The commissural ends of the constructed cusps are suspended at the level of sinotubular bar using transmural pledgeted 4.0 or 5.0 polypropylene sutures. The suspension is tailored to provide optimal cusp edge coaptation but to avoid crowding of the subcommissural triangle.

In patients with severe dilatation of the ventriculoaortic junction, a reduction annuloplasty at the subcommissural area between right and left cusps is performed to enhance coaptation. When the cusp is prolapsed, no attempt is made to excise any portions, but rather to support the prolapsed segment with a strip of autologous pericardium sutured to the edge of the cusp and consequently suspended to the aortic wall as described.
Intraoperative transesophageal, and recently 3-dimensional, echocardiography is typically used to define the anatomy of the valve and to assess the repair (Figure 3).

\section{Statistical Analysis}

Data are expressed as mean \pm standard deviation for continuous variables and as median and range for categoric variables. For comparison of continuous and categoric variables between groups, independent-samples $t$ test and chi-square analyses, respectively, were used. Fisher's exact test was used to detect significant differences between groups. Unpaired 2-tailed $t$ test was performed for comparison of continuous variables between groups. For comparison of preoperative and postoperative data within patients, paired $t$ test analysis was used.

The probability of freedom from events was estimated according to the Kaplan-Meier method. The freedom-from-events estimates were compared with the log-rank test. Univariate analysis was carried out using a $P$ value of less than .05 to determine predictors of early and late freedom from valve reoperation or replacement. The Cox proportional hazards regression model was used to identify variables. Significant factors were entered into a multivariate logistic regression model to assess their independent impact. Because of a high degree of covariance of variables, the analysis was performed repeatedly, removing factors stepwise, to identify the most important variables. The Statistical Package for the Social Sciences 15.0.1 for Windows (SPSS Inc, Chicago, Ill) was used for statistical analysis.

\section{RESULTS}

Twenty-six patients underwent at least 1 intervention before ACEV at The Heart Institute for Children. Twentyfour balloon valvuloplasties were performed in 20 patients. Six patients underwent surgical valvotomy. Another 43 patients (19 with BAVs and 24 with congenital AS) had valvuloplasty or valvotomy (other than ACEV) in outside facilities. No patients required additional valvuloplasty/valvotomy after ACEV. 


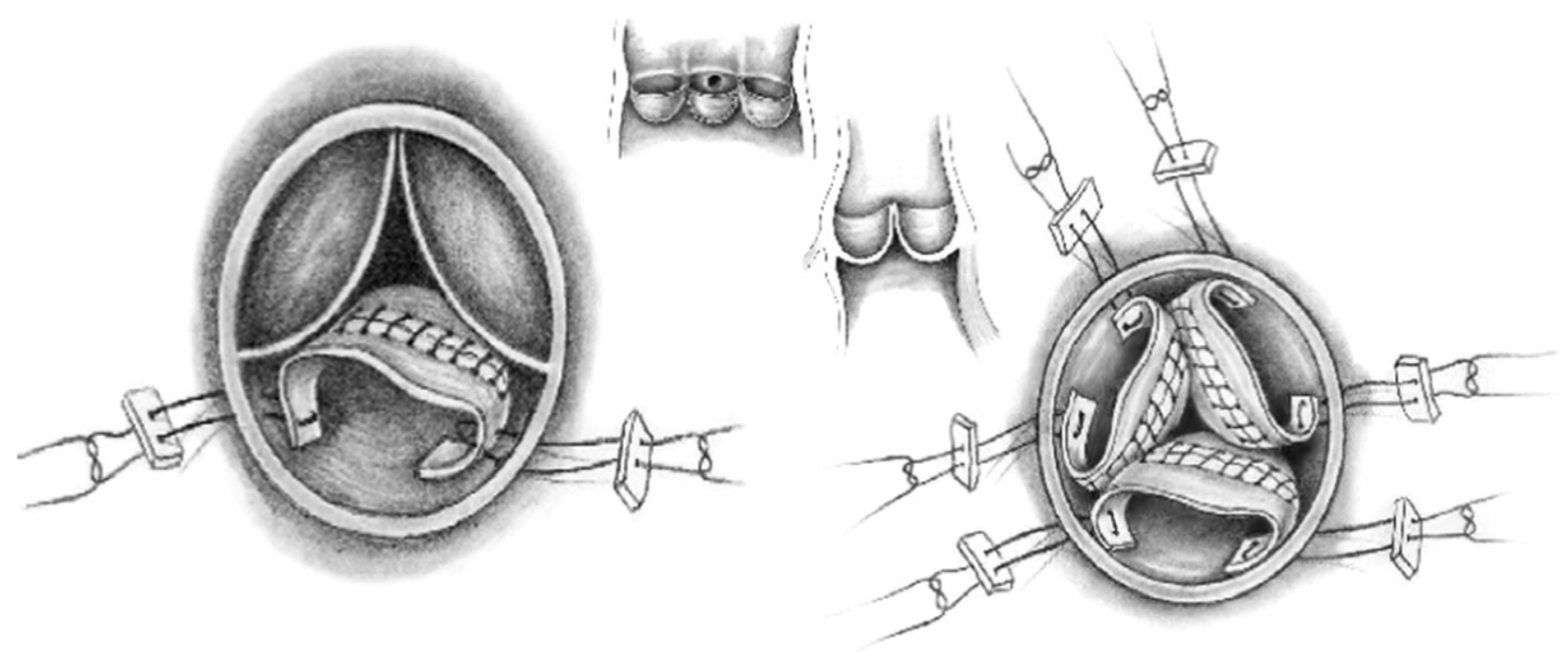

FIGURE 2. ACEV with tricuspidization. The width of each pericardial extension should provide enough additional depth to the cusp so that the reconstructed cusp free edge is level with the sinotubular bar at the commissures but deeper (more caudad) at the center. It is then sutured to the cusp using continuous 5.0/6.0 polypropylene sutures from its center toward the commissures. The sutures are placed in a radial fashion so that the distance between the suture line on the pericardium is slightly wider than that on the cusp to allow for a generous mural edge. After completion of the pericardial extension of the 3 cusps, the depth of each sinus is assessed. As a general rule, the center of the free edge of the constructed cusp should reach the level of the sinotubular bar when pulled superiorly, giving the cusp edge the normal semilunar appearance. The commissural ends of the constructed cusps are suspended at the level of sinotubular bar using transmural pledgeted 4.0 or 5.0 polypropylene sutures. The suspension is tailored to provide optimal cusps edges coaptation yet avoid crowding of the subcommissural triangle.

Before ACEV, AI was severe in 49 patients $(35.2 \%)$ and moderate in 9 patients $(6.5 \%)$. Of those with severe AI, 19 patients had a tricommissural valve with deficiency of 1 or more leaflets (usually right or noncoronary leaflets), 1 patient had a unicommissural valve and central deficiency, and the remaining patients had a bicommissural valve with a central deficiency. In all but 4 of these patients, AI was related to the area of the right or noncoronary cusp. The cause was acquired in 4 patients ( 2 with endocarditis, 2 with rheumatic carditis).

Among patients with only moderate AI, 2 had post-arterial switch operation AI, 6 had traumatic AI after primary valvuloplasty, and 1 had aortic root abscess.

Moderate AS was present in 39 patients $(28 \%)$ : after previous treatment of AS in 26, 12 with BAVs (1 after

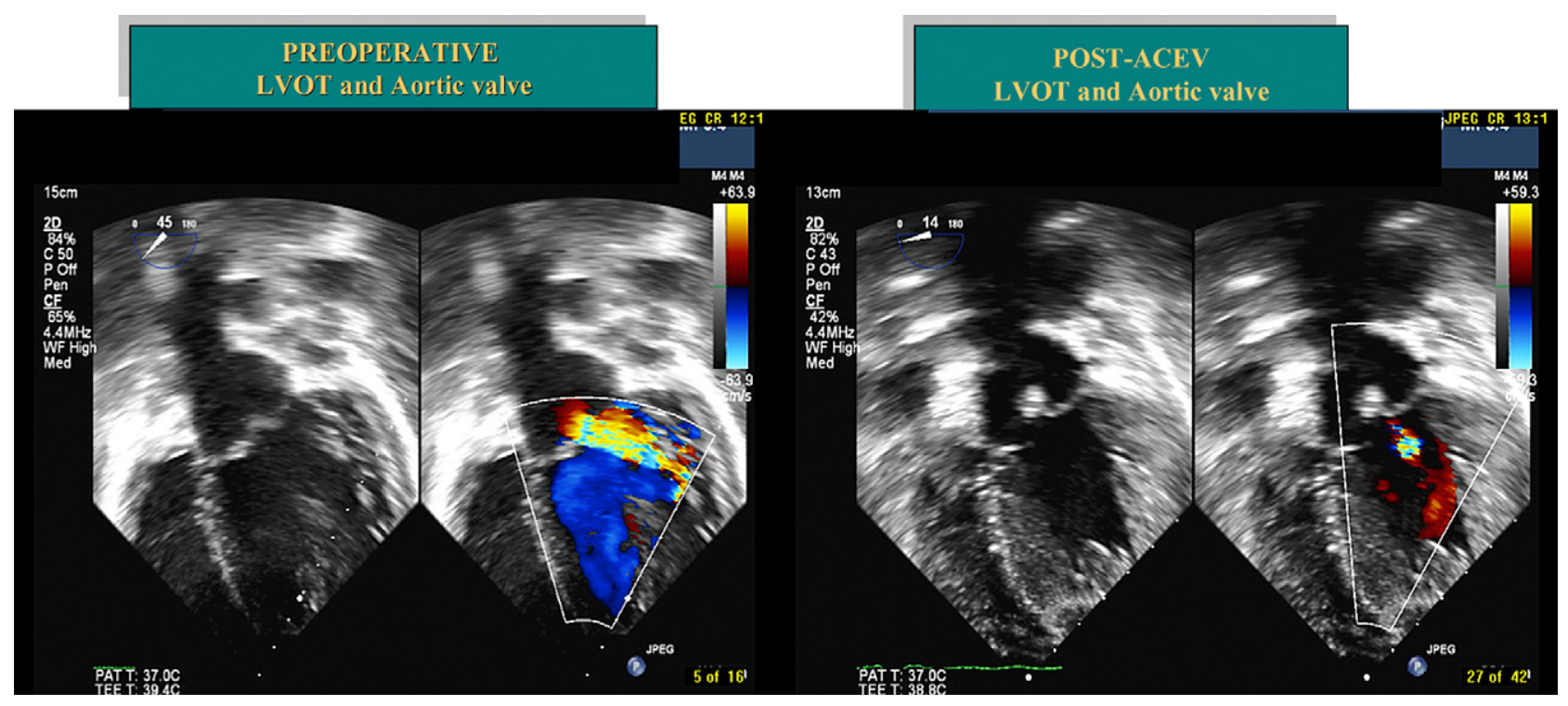

FIGURE 3. ACEV. Perioperative transesophageal echocardiographic assessment. $L V O T$, Left ventricular outflow tract; $A C E V$, aortic cusp extension valvuloplasty. 
primary valvuloplasty for BAVs), and after ventricular septal defect repair in 1.

A combination of moderate-to-severe AS and moderate $\mathrm{AI}$ was present in 42 patients $(30.2 \%)$ : 39 with congenital AS/AI, after primary valvuloplasty treatment for BAVs in 2 , and after primary valvuloplasty for congenital AS in 1.

There were no early, intermediate, or late deaths. After the Ross operation (previously treated congenital AS with balloon valvuloplasty and ACEV), a patient had intraoperative cardiac arrest and as a result had a devastating irreversible neurologic injury.

Crossclamp and CPB times were $69.6 \pm 18.6$ and $95.1 \pm$ 27.6 minutes, respectively. More than mild AS, AI, or combined AS/AI, as documented by echocardiogram, were considered nonacceptable intraoperative outcomes and justified reintervention. On this basis, reinstitution of CPB was required after $8(5.8 \%)$ ACEVs for residual moderate or greater AS, AI, or combined-AS/AI. Re-repair was successfully performed in 6 patients (with only trace/mild AI). Two patients underwent AVR.

ACEV was performed in all 139 patients. Tricuspidization was performed in all patients with BAV. Additional procedures were performed in 8 patients. Ten patients had undergone previous aortic coarctation repair ( 2 with associated ventricular septal defect repair and 2 with subaortic resection), 3 patients underwent an arterial switch operation, and 1 patient underwent repair of an interrupted aortic arch with ventricular septal defect.

Post-ACEV AI or AS was improved in 137 patients. AI or AS was trivial or none in 54 patients $(39 \%)$, mild in 84 patients $(60.3 \%)$, and moderate in 1 patient $(0.7 \%)$ (Table 2$)$.

At most recent follow-up, in patients who underwent AVR (vs those who did not undergo AVR), the degree of AI was severe in 23 patients (vs none, $P<.001$ ) and moderate in 18 patients (vs $3, P<.001)$. The degree of AS for the same group of patients (vs those who had no AVR) was severe in 11 patients (vs none, $P<.001$ ) and moderate in 27 patients (vs $2, P<.001$ ). Z-values of LVEDD, aortic annulus, aortic sinus diameter, sinotubular junction diameter, and LV wall thickness between the 2 groups are shown in Table 2.

During a median follow-up of 14.4 years (0.1-21.4 years), 64 patients underwent aortic valve reinterventions. A second ACEV for recurrent AI or combined AS/AI was performed in 16 patients at a median of 40.6 months (11-116). AVR (Ross procedure or mechanical valve prosthesis) was

TABLE 2. Aortic cusp extension valvuloplasty and results

\begin{tabular}{|c|c|c|c|}
\hline & Iortic cusp extension valvuloplasty & & \\
\hline \multicolumn{4}{|l|}{ Outcomes I } \\
\hline Hospital mortality & 0 & & \\
\hline Cumulative mortality & 0 & & \\
\hline Hospital length of stay (d) & $5.1 \pm 1.3$ & & \\
\hline CPB time (min) & $95.1 \pm 27.6$ & & \\
\hline Crossclamp time (min) & $69.6 \pm 18.6$ & & \\
\hline Pacemaker system implantation & $1(0.7 \%)$ & & \\
\hline Subacute bacterial endocarditis & $1(0.7 \%)$ & & \\
\hline Second ACEV & $16(11.5 \%)$ & & \\
\hline Ross procedure & $32(23 \%)$ & & \\
\hline Prosthetic AVR & $16(11.5 \%)$ & & \\
\hline \multicolumn{4}{|l|}{ Outcomes II } \\
\hline Postoperative ACEV AI or AS: none/trivial & $54(39 \%)$ & & \\
\hline Postoperative ACEV AI or AS: mild & $84(60.3 \%)$ & & \\
\hline Postoperative ACEV AI or AS: moderate & $1(0.7 \%)$ & & \\
\hline Postoperative ACEV AI or AS: severe & 0 & & \\
\hline Outcomes III (at latest follow-up) & Post-ACEV pre-AVR $(\mathrm{n}=48)$ & Post-ACEV no AVR $(\mathrm{n}=91)$ & $P$ value \\
\hline Severe AI & 23 & 0 & $<.001$ \\
\hline Moderate AI & 18 & 3 & $<.001$ \\
\hline Mild/trivial AI & 12 & 88 & $<.001$ \\
\hline Severe AS & 11 & 0 & $<.001$ \\
\hline Moderate AS & 27 & 2 & $<.001$ \\
\hline Mild AS & 14 & 32 & NS \\
\hline LVEDD z-value & $4.2 \pm 3.11$ & $1.8 \pm 1.32$ & $<.001$ \\
\hline Aortic annulus z-value & $2.3 \pm 1.25$ & $1.1 \pm 0.95$ & $<.001$ \\
\hline Aortic sinus diameter z-value & $4.4 \pm 1.21$ & $2.3 \pm 1.91$ & $<.001$ \\
\hline Sinotubular junction diameter z-value & $1.8 \pm 1.28$ & $1.3 \pm 1.03$ & NS \\
\hline LV wall thickness z-value & $2.9 \pm 1.32$ & $1.7 \pm 1.16$ & $<.001$ \\
\hline
\end{tabular}




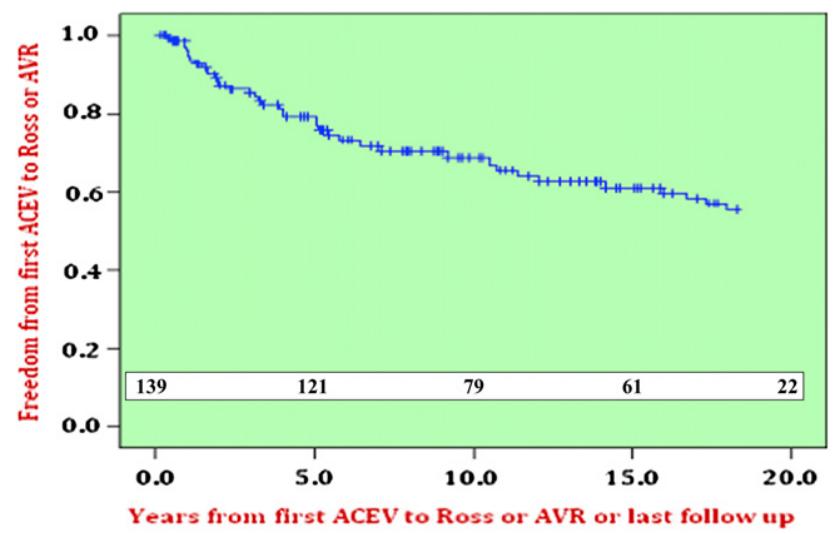

FIGURE 4. Kaplan-Meier estimate of freedom from AVR after ACEV. $A C E V$, Aortic cusp extension valvuloplasty; $A V R$, aortic valve replacement.

performed in 48 patients at a median of 47.2 months (5-172) after ACEV, at a mean age of $14.1 \pm 5.8$ years. In 32 of 139 ACEVs $(23 \%)$, the Ross operation was performed. The Konno operation was added in 2 patients $(6.2 \%)$ undergoing the Ross operation. Other AVRs were performed after 16 ACEVs (11.5\%) (Table 2).

Freedom from any reintervention at 18 years was $50.3 \%$ $\pm 5.3 \%$. Freedom from a second ACEV at $1,5,10$, and 18 years was $99.1 \% \pm 0.9 \%, 88.0 \% \pm 3.3 \%, 82.1 \% \pm 4.2 \%$, and $82.1 \% \pm 4.2 \%$, respectively. Freedom from any type of AVR at $1,5,10$, and 18 years was $97.6 \% \pm 1.4 \%, 79.7 \% \pm$ $4.3 \%, 71.8 \% \pm 5.1 \%$, and $60.0 \% \pm 7.2 \%$, respectively (Figure 4).

By univariate analysis, gender, prior primary valvuloplasty, and weight at first ACEV were not significant factors $(P=$ not significant $)$ for AVR. The risk for AVR increased with longer CPB $(P .001)$ and crossclamp $(P .042)$ times during initial ACEV. BAV was associated with an increased risk for AVR than combined congenital AS/AI $(P<.001)$ and congenital AS ( $P$.005), as was congenital AS compared with combined congenital AS/AI $(P$.008). None or trace residual AS or AI was superior to mild or moderate residual AS or AI after ACEV with regard to freedom from AVR $(P<.001)$. In multivariate analysis, shorter CPB $(P .004)$ and initial diagnosis of combined congenital AS/AI $(P<$ .001) after the first ACEV increased freedom from AVR. In addition, mild or moderate residual AS or AI after the first ACEV was associated with an increased risk for AVR $(P<$ .001) (Table 3).

A third-degree block developed in 1 patient after ACEV, who required a pacemaker at day 12 postoperatively. One patient had subacute bacterial endocarditis 4.4 months after ACEV (Table 2).

\section{DISCUSSION}

Better understanding of the natural history and morphology of congenitally or acquired abnormal aortic valve, advances in surgical techniques and intraoperative myocar- dial protection, and comprehensive postoperative management have contributed to a remarkable improvement in early and late mortality. Applicability, durability, and long-term outcomes of different types of aortic valve repair have not been thoroughly analyzed.

This series was intended to focus on patients with complex anatomy in whom ACEV with tricuspidization (when needed) was exclusively used. Simple lesions, such as isolated AS, less than moderate AI, or simple iatrogenic-associated AI, for which the usual techniques of repair have proved durable, were excluded. ${ }^{11-15}$ Balloon or surgical aortic valvuloplasty may be an effective and safe initial treatment for patients with AS. ${ }^{16,17}$ Contrary to other reports, ${ }^{18}$ no patients had any form of surgical or balloon valvuloplasty after ACEV.

In our experience, ACEV was effective at acutely reducing AI or AS and improving LV wall mass thickness and dimensions in children and adolescents with AI or AS from a variety of causes. Other investigators have reported similarly promising early outcomes after ACEV in children and adolescents with congenital heart disease, although most series are relatively small or include simple and complex repairs. ${ }^{7-14,18,19}$ Nevertheless, the literature suggests that ACEV is effective in the short term and, as well shown in this study, allows expeditious LV remodeling even in patients with significant LV dilation or wall mass thickness with satisfying long-term durability and freedom from AVR.

Despite the limited data regarding advanced valvuloplasty techniques in children with complex aortic valve disease, the literature concerning the use of pericardial leaflet extension in both children and adults with rheumatic AI and in adults with $\mathrm{AI}$ and a structurally normal aortic valve demonstrates that repairs incorporating pericardial augmentation of cusps can be fairly durable. ${ }^{13-15,18,19}$ There are several important features related to ACEV with tricuspidization. It provides a comprehensive repair and restores all the important anatomic features of the aortic valve. By fashioning the pericardial patch to fit the deficient parts of each cusp, normal depth of the sinuses is reestablished and adequate cusp coaptation is secured. Cusp resuspension at the level of sinotubular bar without central valve crowding and wide subcommissural triangle are essential elements of ACEV. Furthermore, tricuspidization restores central flow characteristics and, thus, decreases turbulence and subsequent trauma to the repaired cusps. The ultimate outcomes are often contingent on the performance of the patch used. We have no experience with patch substitutes other than autologous pericardium at the present time. Autologous pericardium is fairly pliable and easily accessible, and can be fashioned to any shape needed. Concentration of glutaraldehyde solution and duration of preinsertion pericardial treatment have varied throughout the study period. In our early series, the pericardial extensions were often heavily calcified and contracted, presumably contributing to progressive post-ACEV aortic 
TABLE 3. Incremental risk factors associated with reoperation for aortic valve replacement after aortic cusp extension valvuloplasty: Univariate and multivariate Cox regression analyses

\begin{tabular}{|c|c|c|c|c|c|c|}
\hline & Univariate Cox model & & & Multivariate Cox model & & \\
\hline Variable & HR & $95 \% \mathrm{CI}$ & $P$ & HR & $95 \% \mathrm{CI}$ & $P$ \\
\hline Gender & 1.29 & $(0.69-2.42)$ & .43 & & & \\
\hline Younger age at ACEV $(<9.3 \mathrm{y})$ & 0.98 & $(0.94-1.02)$ & .36 & 0.92 & $(0.87-0.98)$ & .004 \\
\hline Prior plasty & 1.54 & $(0.80-2.99)$ & .21 & & & \\
\hline Weight at ACEV & 1.00 & $(0.98-1.01)$ & .71 & & & \\
\hline ACEV CPB time (min) & 1.02 & $(1.01-1.03)$ & .001 & 1.02 & $(1.01-1.03)$ & $<.001$ \\
\hline $\begin{array}{l}\text { ACEV crossclamp } \\
\text { time (min) }\end{array}$ & 1.01 & $(1.00-1.02)$ & .042 & ${ }^{*}$ & & \\
\hline BAV & 2.88 & $(1.62-5.13)$ & $<.001$ & 0.08 & $(0.02-0.34)$ & $<.001$ \\
\hline Combined congenital AS/AI & 0.63 & $(0.33-1.22)$ & .16 & & & \\
\hline Congenital AS & 0.09 & $(0.02-0.38)$ & $<.001$ & 0.42 & $(0.20-0.85)$ & .013 \\
\hline Aortic coarctation & 2.54 & $(1.07-6.02)$ & .058 & & & \\
\hline ACEV residual AS or AI & 7.00 & $(2.76-17.73)$ & $<.001$ & 6.02 & $(2.29-15.81)$ & $<.001$ \\
\hline
\end{tabular}

$H R$, Hazard ratio; $C I$, confidence interval; $A C E V$, aortic cusp extension valvuloplasty; $C P B$, cardiopulmonary bypass; $B A V$, bicuspid aortic valve; $A S$, aortic stenosis; $A I$, aortic insufficiency. *Not included in multivariate model.

valve dysfunction. Currently, the pericardium is treated with $0.625 \%$ glutaraldehyde solution for shorter duration (3 minutes), compared with our early experience, ${ }^{20}$ and kept moist with normal saline. This might promote increased pericardial pliability and decrease the incidence of restenosis; however, the effect of this modification has yet to be determined.

The optimal timing and method of intervention remain a challenging task. Guidelines for aortic valve surgery in this patient population traditionally have been developed on the basis of those for adults. Results with ACEV encourage earlier and more aggressive management in pediatric patients because the LV has to preserve function for a longer life span. On the basis of our experience and those of others, ${ }^{7,10,13,14,17-19,21}$ we advocate ACEV in all patients with moderate or severe $\mathrm{AI}$, moderate $\mathrm{AS}$, or a combination of moderate-to-severe AS and moderate AI as long as they have a normally sized aortic annulus (z-value, -1.5 or greater) without LV hypoplasia or mitral valve hypoplastic annulus (z-value, -2.0 or smaller). Timing is rather critical. Several echocardiographic/Doppler-derived indices, such as pressure gradient, LV hypertrophy progression, LVEDD $\mathrm{z}$-value, and ratio of regurgitant jet/annulus diameter (as previously described), may guide optimal timing and strategy.

Mid- and long-term survival varies in the literature. $^{6-15,18,19}$ There were no early, intermediate, or late deaths in our series.

Although freedoms from any aortic valve reintervention or AVR vary between different series, published studies have demonstrated progressively decreasing freedom from aortic valve reintervention after various surgical valvuloplasty techniques. ${ }^{10-14,18,19,21}$ Ours is among the longest in the literature.

One of the potential adverse outcomes of ACEV for AI in patients with congenitally abnormal valves is postoperative AS. This is a particular concern in patients in whom AI developed after balloon or surgical valvuloplasty for AS. ${ }^{16,17}$ In our experience, new or worsening AS after ACEV was rare. However, AS did develop over time. The cause of this progressive AS is not clear, but pericardial calcification or contraction might contribute. In those who underwent $\mathrm{AVR}$, the degree of $\mathrm{AS}$ at the most recent follow-up after ACEV was severe in $7.9 \%$ and moderate in $19.4 \%$. On the basis of this observation, we have recently favored the Ross procedure over ACEV in patients with moderate/severe AS and aortic annulus with z-value $\leq$ -1.5 because of the concern for early failure and recurrence of AS over time.

In contrast with the findings of others, ${ }^{22}$ the $\mathrm{z}$-values of LVEDD, aortic annulus, aortic sinus diameter, sinotubular junction diameter, and LV wall thickness, which improved after ACEV, remained relatively stable at follow-up in patients who met no AVR criteria at the latest follow-up after ACEV.

On the basis of multivariate regression analysis, shorter $\mathrm{CPB}$ and initial diagnosis of combined congenital AS/AI at the first ACEV increase freedom from AVR. In addition, mild or moderate residual AS or AI after the first ACEV is associated with an elevated risk for AVR. LV dimensions typically normalize or improve substantially after ACEV even when severe dilation is present. ACEV allows substantial delay of AVR for most patients, which may facilitate eventual AVR with a larger prosthesis or Ross procedure. As a result, with improved patient selection and surgical techniques, the durability of ACEV should continue to improve.

There are advocates of the Ross procedure as first-line management in children and adolescents with congenitally abnormal aortic valve disease and a normally sized aortic annulus. ${ }^{3-5,23-25}$ Our experience with ACEV in this complex population with aortic valve disease suggests that unless 
certain criteria are fulfilled (as outlined above), and despite certain drawbacks, the Ross procedure or prosthetic AVR remains an alternative to ACEV in our practice. The Ross procedure involves replacement of the entire aortic root, with reimplantation of the coronary arteries, as well as placement of a valved conduit between the right ventricle and the pulmonary arteries. Apart from the need for conduit replacement, there is increasing evidence of significant progressive neoaortic root dilation and autograft failure. As an alternative to the Ross procedure, prosthetic AVR involves a risk of early and late mortality in younger children receiving smaller mechanical valves. It is associated with increased frequency of complications, including morbidity related to long-term anticoagulation if mechanical prosthesis is used, deterioration of ventricular function caused by the development of patient-prosthesis mismatch as the child outgrows the initial valve, and the need for subsequent prosthetic valve replacement. ${ }^{5,23-25}$

\section{Study Limitations}

The limitations of our study involve all the aspects of a clinical retrospective, nonrandomized comparison analysis. This study is limited by the heterogeneous patient population and by the fact that referral for surgery was subjective in most cases. Furthermore, this experience encompasses a period when the techniques of ACEV were under development. Regular serial echocardiographic assessment of pre-ACEV geometry and function was not available, which limits our insight into the evolution of changes in aortic valve function and LV size and function with time. A study is in progress to evaluate the 3-dimensional echocardiographic parameters of an abnormal aortic valve that may help to guide selective intraoperative management. Finally, despite the relative benefits and drawbacks of ACEV in comparison with therapeutic alternatives, this study cannot be considered for direct comparison between ACEV and AVR.

\section{CONCLUSIONS}

ACEV is a safe, effective, and reproducible surgical option with excellent survival and good long-term outcomes in children and adolescents with congenital or acquired aortic valve disease. We favor the Ross or Ross-Konno operation over ACEV in patients with moderate/severe AS and aortic annulus with z-value $\leq-1.5$ because of the concern for early failure and recurrence of AS over time. Patients with a normally sized aortic annulus who have moderate or severe AI, moderate AS, or a combination of moderateto-severe AS and moderate AI should be considered for ACEV with tricuspidization (when needed). Pressure gradient, LV hypertrophy progression, LVEDD z-value, and ratio of regurgitant jet/annulus diameter may guide optimal timing and strategy. ACEV provides acceptable durability and satisfactory freedom from AVR.

\section{References}

1. Duran CM, Alonso J, Gaite L, Alonso C, Cagigas JC, Marce L, et al. Long term results of conservative repair of rheumatic aortic valve insufficiency. Eur J Cardiothorac Surg. 1988;2:217-23.

2. Karamlou T, Jang K, Williams WG, Caldarone CA, Van Arsdell G, Coles JG, et al. Outcomes and associated risk factors for aortic valve replacement in 160 children: a competing-risks analysis. Circulation. 2005;112:3462-9.

3. Lupinetti FM, Duncan BW, Lewin M, Dyamenahalli U, Rosenthal GL. Comparison of autograft and allograft aortic valve replacement in children. J Thorac Cardiovasc Surg. 2003;126:240-6.

4. Laudito A, Brook MM, Suleman S, Bleiweis MS, Thompson LD, Hanley FL, et al. The Ross procedure in children and young adults: a word of caution. J Thorac Cardiovasc Surg. 2001;122:147-53.

5. Elkins RC, Lane MM, McCue C. Ross operation in children: late results. J Heart Valve Dis. 2001;10:736-41.

6. Bacha EA, Satou GM, Moran AM, Zurakowski D, Marx GR, Keane JF, et al. Valve-sparing operation for balloon-induced aortic regurgitation in congenital aortic stenosis. J Thorac Cardiovasc Surg. 2001;122:162-8.

7. Caspi J, Ilbawi MN, Roberson DA, Piccione W, Monson DO, Najafi H. Extended aortic valvuloplasty for recurrent valvular stenosis and regurgitation in children. J Thorac Cardiovasc Surg. 1994;107:1114-20.

8. Hasaniya N, Gundry SR, Razzouk AJ, Mulla N, Bailey LL. Outcome of aortic valve repair in children with congenital aortic valve insufficiency. $J$ Thorac Cardiovasc Surg. 2004;127:970-4.

9. Hawkins JA, Minich LL, Shaddy RE, Tani LY, Orsmond GS, Sturtevant JE, et al. Aortic valve repair and replacement after balloon aortic valvuloplasty in children. Ann Thorac Surg. 1996;61:1355-8.

10. De La Zerda DJ, Cohen O, Fishbein MC, Odim J, Calderon CA, Hekmat D, et al. Aortic valve-sparing repair with autologous pericardial leaflet extension has a greater early re-operation rate in congenital versus acquired valve disease. Eur J Cardiothorac Surg. 2007;31:256-60.

11. Tweddell JS, Pelech AN, Frommelt PC, Jaquiss RD, Hoffman GM, Mussatto KA, et al. Complex aortic valve repair as a durable and effective alternative to valve replacement in children with aortic valve disease. J Thorac Cardiovasc Surg. 2005;129:551-8.

12. Alsoufi B, Karamlou T, Bradley T, Williams WG, Van Arsdell GS, Coles JG, et al. Short and midterm results of aortic valve cusp extension in the treatment of children with congenital aortic valve disease. Ann Thorac Surg. 2006;82:1292-9.

13. Bozbuga N, Erentug V, Kirali K, Akinci E, Isik O, Yakut C. Midterm results of aortic valve repair with the pericardial cusp extension technique in rheumatic valve disease. Ann Thorac Surg. 2004;77:1272-6.

14. Al Halees Z, Al Shahid M, Al Sanei A, Sallehuddin A, Duran C. Up to 16 years follow-up of aortic valve reconstruction with pericardium: a stentless readily available cheap valve? Eur J Cardiothorac Surg. 2005;28:200-5.

15. Vida VL, Bottio T, Milanesi O, Reffo E, Biffanti R, Bonato R, et al. Critical aortic stenosis in early infancy: surgical treatment for residual lesions after balloon dilation. Ann Thorac Surg. 2005;79:47-52.

16. Fratz S, Gildein HP, Balling G, Sebening W, Genz T, Eicken A, et al. Aortic valvuloplasty in pediatric patients substantially postpones the need for aortic calve surgery. Circulation. 2008;117:1201-6.

17. Chartand CC, Saro-Servando E, Vobecky JS. long-term results of surgical valvuloplasty for congenital valvar aortic stenosis in children. Ann Thorac Surg. 1999; 68:1356-60.

18. Bacha EA, McElhinney DB, Guleserian KJ, Colan SD, Jonas RA, del Nido PJ, et al. Surgical aortic valvuloplasty in children and adolescents with aortic regurgitation: acute and intermediate effects on aortic valve function and left ventricular dimensions. J Thorac Cardiovasc Surg. 2008;135:552-9.

19. Kalangos A, Beghetti M, Baldovinos A, Vala D, Bichel T, Mermillod B, et al. Aortic valve repair by cusp extension with the use of fresh autologous pericardium in children with rheumatic aortic insufficiency. J Thorac Cardiovasc Surg. 1999; 118:225-36.

20. Ilbawi MN, DeLeon SY, Wilson WR, et al. extended aortic valvuloplasty: a new approach for the management of congenital valvar stenosis. Ann Thorac Surg. 1991;52:663-8.

21. McMullan DM, Oppido G, Davies B, Kawahira Y, Cochrane AD, d'Udekem d'Acoz Y, et al. Surgical strategy for the bicuspid aortic valve: tricuspidation with cusp extension versus pulmonary homograft. $J$ Thorac Cardiovasc Surg. 2007; $134: 90-8$

22. Tafreshi RI, Shahmohammadi A, Davari PN. Predictors of left ventricular performance after valve replacement in children and adolescents with chronic aortic regurgitation. Pediatr Cardiol. 2005;26:331-7. 
23. Hazekamp MG, Grotenhuis HB, Schoof PH, Rijlaarsdam MA, Ottenkamp J, Dion RA. Results of the Ross operation in the pediatric population. Eur J Cardiothorac Surg. 2005;27:975-9.

24. Mavroudis C, Backer CL, Kaushal S. Aortic stenosis and aortic insufficiency in children: impact of valvuloplasty and modified Ross-Konno procedure. Semin Thorac Cardiovasc Surg Pediatr Card Surg Ann. 2009;12:76-86.

25. Alsoufi B, Al-Halees Z, Manlhiot C, McCridle BW, Al-Ahmadi M, Sallehuddin A, et al. Mechanical valves versus the Ross procedure for aortic valve replacement in children: Propensity-adjusted comparison of long-term outcomes. J Thorac Cardiovasc Surg. 2009;137:362-70.

\section{Discussion}

Dr Ross M. Ungerleider, MD (Cleveland, Ohio). The topic is timely. It is controversial and important as we try to find ways to extend the time before valve replacement in our young population.

I want to ask you some questions that can help us understand when to use your techniques in lieu of more conventional treatments. I have spent a lot of time trying to understand the numbers in your article and the numbers you presented today. Your study, as you mentioned, is retrospective. It lacks comparison with a control group treated by more conventional means, and as you mentioned it also is subject to selection bias. You mentioned that you only selected the patients with more complex problems. The patients with more typical problems were treated by more usual techniques. So for which patient is ACEV with or without tricuspidization more desirable than simple balloon valvotomy? You had 50 patients with BAV and 40 patients with congenital AS, most aged more than 2 years. These patients would likely be treated in most centers by balloon valvotomy, but only $20 \%$ of your patients in these groups have balloon valvotomy before ACEV. Can you give us insight into why you selected your patients for ACEV versus valvotomy and do you have any outcome data comparing them with the patient groups that you apparently selected for simple valvotomy? I am having trouble understanding why an ACEV was necessary for these patients with predominant AS.

The literature would tend to support that freedom from AVR is excellent after balloon valvotomy for older patients similar to the ones in your series. For the patients who had AI, you had 41 patients with AS/AI and 8 patients with what you called other valve pathology, yet you state that 49 patients received ACEV for severe AI and an additional 9 patients received ACEV for moderate AI. Does that number include a crossover from the bicuspid or congenital AS group? As I looked at your numbers, it appeared that $44 \%$ of patients in your series had ACEV for AI, leaving 56\% having ACEV for predominantly AS. This is potentially useful data for you to have because you can create some comparison groups. Do you have data to show if there is a difference in the freedom from AVR in one group versus another? In particular, it might be useful if you could compare for us the results of ACEV for AI versus ACEV for AS and then ACEV plus tricuspidization for AS, which is a uniquely different treatment group.

I am particularly concerned that you have not really explained to us the benefits of tricuspidization compared with simple valvotomy for BAV, and it would be helpful if you could determine whether the ACEV group fared better than the balloon valvotomy group for AS in terms of putting off the time until AVR in these similar-aged patients. I am puzzled about the role for ACEV. Without randomization and comparison with controls (simple valvotomy), it is difficult to understand whether there is any useful role for ACEV as you have described it.

You mentioned that you changed to a less intense fixation of pericardium to improve the results of your ACEV, yet you don't give us any indication of what the problems were with the more intensely treated pericardium. I wonder if you have any experience with polytetrafluoroethylene (Gore-Tex; WL Gore \& Associates, Newark, DE) membrane for aortic cusp valve extension. I have had good results so far with that.

Finally, going forward with your experience, as you help us understand when to select patients for ACEV, what would you recommend for a 6-year-old with BAV, a normal annulus, a mean gradient of $60 \mathrm{~mm} \mathrm{Hg}$, no AI, and an increase in LV wall mass?

Dr Polimenakos. Starting with your first comment and question, I would say that most of these patients who present actually require complex repair. We excluded patients who had simple valvotomies or valvuloplasties that did not require extensive reconstruction in the form of ACEV. That includes a group of patients who had original valvotomy or valvuloplasty, and they did not reach that level of AI to justify ACEV. As I mentioned to you before, I think if we have a gradually increased LVED after balloon valvuloplasty, in that subset of patients you mentioned, and in addition to that there is a regurgitant jet to aortic annulus diameter greater than $35 \%$ to $40 \%$, we recommend ACEV for these patients.

I totally agree with you that the specific subset of patients with congenital AS is a group with early failure and recurrent AS. That is why according to the original experience, over the last few years we have been very selective offering ACEV to this subcategory of patients. We encourage these patients to have some form of valve replacement (probably in the form of Ross), particularly the smaller patients.

In terms of your second question, there are some crossovers as you mentioned. That is because a lot of the patients with BAV had either predominantly AI when they presented to us, as a referral center, or combined AI/AS. Some of them had even balloon valvuloplasty before that. That is why, as I mentioned, it is not a simple repair that we just reinforce the commissure or repair a torn cusp. Most of these patients have moderate to severe AI or a combination AI and AS. Again, patients with congenitally related AS were one of the subgroups originally attempted to be repaired, but currently we do not recommend this technique, especially if the aortic valve annulus has a $\mathrm{z}$-value of -1.5 or less.

In terms of your final question, this is actually an ongoing study. We are going to look into the different surgical eras because, as I mentioned to you before, we moved from glutaraldehyde-treated autologous pericardium with 10 minutes of glutaraldehyde treatment gradually down to, currently, 3 minutes.

Dr Ungerleider. But you switched because you were seeing more progressive AI?

Dr Polimenakos. We were seeing more neocusp calcification and fibrosis with predominantly AI. Some of these patients presented with combined recurrent $\mathrm{AI}$ and $\mathrm{AS}$ as well. 